\title{
Fair Shares and Families: a Child-Focused Model of Intra-Household Sharing
}

Gill Main ${ }^{1}$

Accepted: 2 April 2019 / Published online: 8 July 2019

(C) The Author(s) 2019

\begin{abstract}
This article proposes a child-centric model for intra-family allocation - the sharing of resources within families - based on children's and families' accounts and reports of their experiences and perspectives. Studies of intra-household allocation have highlighted complex processes and outcomes within the 'black box' of the household, including inequities according to gender and parental prioritising of children's needs when circumstances are constrained. Unsurprisingly, inequalities favouring children tend to be most pronounced among households attempting to manage on lower incomes, as the resources available for sharing are scarcer. However, children's views have been notably absent from most studies, and the issue of intrahousehold allocation is complicated by increasing numbers of children living across multiple households - hence the focus here on intra-family, rather than intra-household, allocation. The model proposed here identifies four key dimensions of intra-family allocation, based on a longitudinal mixed-methods study with children and families in England. The model highlights the problematic nature of using the household as a unit of measurement when children are the unit of interest and/or analysis; and will be valuable in developing a more nuanced understanding of children's material well-being.
\end{abstract}

Keywords Child poverty Intra-household sharing $\cdot$ Child well-being $\cdot$ Child-centric

\section{Background}

Children's material living standards are the focus of a large body of research, and are an important determinant of child well-being. Material well-being - and at one end of the material well-being continuum, poverty - is associated with diverse domains of children's well-being, during childhood and in relation to children's movement towards, and outcomes in, adulthood (e.g. see Griggs and Walker 2008; Bradshaw 2016). An important focus of research on child poverty has been establishing appropriate methods for measurement, including the indicators

Gill Main

G.Main@leeds.ac.uk

1 School of Education, University of Leeds, Leeds, UK 
which should be used in assessing children's poverty status. Two elements of this body of literature form the basis for the research presented in this paper. Firstly, the predominance of the household as a unit of measurement in studies of child poverty; and secondly the tendency to rely on adult, usually parental, reports in relation to the resources which children have access to. These are discussed in turn next.

\subsection{The Use of the Household as a Unit of Measurement}

While there is a broad consensus that material well-being - and specifically poverty - is multidimensional, household income has remained the predominant measure in most studies. The measurement of household income is vitally important; as Cooper and Stewart (2013) have demonstrated, household income is causally linked to a range of important child outcomes. However, it also relies on assumptions which complicate the study of material well-being at the level of individuals (see Main 2018a). Two main issues with the use of income which are particularly pertinent to this paper are its inability to capture inequalities between different members of the same household, and the implicit assumption that individuals are easily assignable to a single, relatively stable household. These are now addressed in turn.

For several decades, research into within-household distributions has confirmed that assumptions of equitable sharing of resources within households - whether these comprise income or other material and social resources - are not met. Bennett's (2013) summary of studies of intra-household allocation confirms persistent differences based on gender, relating to both processes (how couples negotiate the sharing of resources) and outcomes (who gets what) within heterosexual couples. Middleton et al.'s (1997) finding that parents in poverty tend to sacrifice their own needs in order to provide for their children has been replicated in more recent research (e.g. Main and Bradshaw 2016); and research with children confirms their own active roles in forming perceptions on their material needs which both complement and contrast with parental perceptions, and on the fairness of allocation processes and outcomes within their families (Ridge 2002; Main 2013). However, children remain largely unrepresented in studies of material well-being (see "Reliance On Parental Reports" section for a discussion on reliance on parental reports), and are often treated as passive adjuncts to parents and a net drain on household resources. This assumption is problematic across childhood, and increasingly so as children get older and exercise more autonomy in their activities and use of resources. It is also problematic in situations where children's family and household membership is complex, discussed next.

Changes in social norms around and patterns of family formation result in increasing complexity in assigning children to a single household, and justifying the assumption that their material well-being is determined (primarily or exclusively) by the income inputted to that household. Olah et al. (2017) provide a detailed discussion of the changing and increasingly diverse make-up of families across the European Union. Multiple issues are raised by these changes, including (but by no means limited to) deciding which household to allocate children to, especially in the context of an increasing prevalence of shared care in postseparation families; accounting for resources that children may (or may not) carry between the different households of which they are a member, and the practical, emotional and relational implications of such resource moves; and the potential for different children within the same household to receive differential inputs from non-resident parents, for example in cases where step- or half-siblings receive resources from different parents (see Davies (2015) 
for an illustration of these issues). All of these issues contribute to important and increasingly prevalent difficulties in the use of the household as a unit of measurement in assessing children's material well-being. Even when parents are asked to report on children's access to child-specific resources, as discussed in the next section, this complexity is generally lost.

\subsection{Reliance on Parental Reports}

One way of moving beyond the household as unit of measurement which has been adopted in a range of studies is to investigate individual access to resources, including individual incomes but more pertinently looking at the material and social resources which different members of a household have access to (for example the European Survey on Income and Living Conditions includes modules on individual material deprivation, and within the UK the Family Resources Survey and the UK Poverty and Social Exclusion Survey include detailed lists of personal as well as household deprivation items). Within these surveys, each adult member of the household is asked to report on their own access to resources, and a nominated parent is asked to report on whether any child within the household lacks access to child-specific resources (Burchardt and Karagiannaki 2018). Dermott and Main's (2018) edited collection on the risk of poverty for different population groups based on the UK Poverty and Social Exclusion Study offers an example of how such an approach can add valuable information about hidden poverty risks among some sectors of the population. But as with all approaches, there are limitations to what this can tell us about the actual material well-being of individuals. For the purposes of this paper, these limitations fall into two broad categories, relating to the accuracy of data supplied by parents, and the different perspectives which parents and children may have about access to, and the importance of, different resources. These are now examined.

Surveys including parental reports on child access to resources provide important data in relation to our understandings of child poverty. Middleton et al. (1997) and more recently Main and Bradshaw (2016) demonstrate that parents in constrained circumstances prioritise children's needs over their own, and are more likely than the children they live with to economise and go without comparable necessities, to ensure children have access to these. However, these reports are based on parental perceptions of which resources are important, the resources children have access to, and how these resources should be prioritised. Main's (2013) analysis of parent-child pair responses to deprivation questions found that children and adults provide similar responses in relation to whether the child has access to a particular resource, but differ substantially in whether they see the resource as a necessity. Several hypotheses have been suggested to explain areas of difference. One hypothesis is that parents may not be aware of the resources that children - particularly older children - have access to. This may be a result of children deliberately or unintentionally hiding their (lack of) access to resources from parents (e.g. Ridge 2002; Main 2018b). A second is that the shame associated with being unable to provide perceived necessities for children may result in non-response or under-reporting (see Chzhen et al. 2014). Thirdly, children's access to resources may differ across different households to which they belong. And finally, different children within the same household may have differential access to resources, especially in situations where there are different non-resident parents potentially contributing different levels of resources for the child (see Davies 2015). Therefore, although parental reports provide invaluable information on children's material living standards, it is reasonable to assume that such information is incomplete and potentially at times inaccurate. 
Another complicating factor in the use of parental reports is that parents and children may differ in their perspectives on whether children have access to particular resources, and how different resources should be prioritised. Focus groups with children conducted as part of Main's (2013) research identified that while children and parents are similar in their prioritisation of resources relating to health, education and development, children also emphasise the importance of fitting in with other young people, and having fun during childhood. Parents were perceived by some children as minimising the importance of these resources - a finding which is confirmed in Main and Bradshaw's (2018) analysis of parental prioritisation of children's resources in different domains. Some items commonly included in deprivation indices - for example a family car and a safe space outside where children can spend time (Main and Bradshaw 2018; Main 2013) - may be perceived very differently by parents compared to children (who may, for example, know that their family has a car but feel that their requests for transportation are not always granted). These considerations indicate that a more nuanced approach to understanding children's material living standards, to complement existing, broad-brush measures, is indicated.

\section{Research Questions and Aims}

As a result of the issues in measuring children's material well-being detailed above, the purpose of this paper is to investigate how children's active roles in the sharing of household resources can be integrated into the understanding and measurement of children's material living standards. I aim to identify different aspects of children's integration into family resource-related decision making which contribute to their overall living standards, with a view to proposing a child-centric model of intra-family sharing. This model will have implications for academic research, policy, and practice.

\section{Methods and Data}

This article draws on data collected for the Fair Shares and Families study. ${ }^{1}$ The aim of Fair Shares and Families is to develop a more detailed knowledge of the links between child poverty and children's subjective well-being, via a focus on children's and families' experiences and perceptions of how family resources are shared. Longitudinal mixed methods have been used to generate both rich, contextual data on how families go about sharing their resources, alongside representative survey data for children aged 10-17 in England. The development of the theoretical model presented in this paper draws on both project strands, and further details of the different methods are presented next.

\subsection{Qualitative Strand}

The qualitative strand of the project involved in-depth research with eight families, based in two cities. Both cities are located in the north of England, but differ substantially in their demographics; one is a large, ethnically diverse city with high levels of poverty, while the other is a small, relatively affluent city with a predominantly white British population. Families representing a wide range of socio-economic backgrounds and family structures were sampled, focusing on a 'reference child' within the age range of 10-16. Details of the sample are shown in Table 1. Fieldwork

\footnotetext{
${ }^{1}$ Funded by the ESRC Future Research Leaders scheme, grant number ES/N015916/1.
} 
Table 1 Participant information table: qualitative strand

\begin{tabular}{llllll}
\hline Reference & Location & Structure & Children & Income $^{\mathrm{a}}$ & Ethnicity \\
\hline 1 & Large city & Two parent & M16; M16 & High & White British and White Irish \\
2 & Large city & Two parent & M18; F13 & Medium-high & White British \\
3 & Small city & Two parent & M10; F6 & High & White British and Spanish \\
4 & Small city & Lone parent & F15; M13; M9 & Low & White British \\
5 & Small city & Step family & F15; M10 & Medium-low & White British and Latin American \\
6 & Small city & Two parent & F13; M10 & Medium-high & White British \\
7 & Small city & Lone parent & F11 & Low & White British \\
8 & Small city & Two parent & M11; M11 & High & White British \\
\hline
\end{tabular}

a The income level of the family was ascertained through an initial questionnaire; if families were not willing to provide income data, an assessment was made based on observations of their living conditions and data generated in the qualitative study

with families comprised family group interviews, $1-1$ interviews with family members, separate group interviews with parents and with sibling groups, photo-elicited interviews, observations, and games. Interviews were recorded and transcribed, and field notes were made on observations and the research process in general. The duration of families' participation in the research depended both on the timing of their recruitment to the study, and their preferences; most families engaged in fieldwork for a period of several weeks, enabling the researcher to observe changes over time, return to topics of particular interest, and incorporate new topics as these arose in the fieldwork with the sample of families.

Qualitative data were analysed thematically and iteratively, with themes initially deriving from the literature and within the qualitative data; these were then supplemented with themes emerging from the quantitative strand of the research.

\subsection{Quantitative Strand}

The quantitative strand of the project comprised a three-wave panel survey, conducted at sixmonthly intervals. The survey was designed by the project team, and included 100 questions per wave. Survey questions included demographic information collected from both parents and children; pre-existing measures such as the Student's Life Satisfaction Scale (Huebner 1991) and the Child Deprivation Scale (Main 2013); and new questions which were developed based on emerging findings from the qualitative strand of the research, which were extensively tested and piloted with children and parents before inclusion in the final survey. Some questions remained the same across the three survey waves, while other questions changed in light of emerging findings from the qualitative strand of the research. Data were collected via an online survey run by $\mathrm{BMG},{ }^{2}$ a research agency with access to a large panel of children and families. Data were passed on to the researchers in anonymised form. A sample of 1000 child-parent pairs, representative of children in England based on age, gender, and socio-economic status, was sought. The decision was made to prioritise a sample representative of children, over a sample representative of adults - resulting in a strong gender bias among parent respondents. Attrition between survey waves was addressed through replacement with children of similar characteristics to those who dropped out of the

\footnotetext{
$\overline{2}$ BMG http://www.bmgresearch.co.uk/
} 
study. At the time of writing, two waves of the survey have been completed with an attrition rate of about $40 \%$. Some demographic characteristics of the sample including the age and gender of the child, and the gender, ethnicity and socio-economic grade of the parent, are shown in Table 2.

Survey data were analysed using Stata, drawing on a range of descriptive and multivariate methods. Weights were calculated to ensure that the sample was representative of England in relation to the child's age and gender, and socio-economic status of the household of the participating parent. All analyses were run both with and without weighting, and there were minimal differences in results based on using the weights. Analyses informing the findings presented here comprise descriptive statistics and bivariate analyses - more complex quantitative analysis are presented in Main (2018a) and will be the subject of further project outputs.

\subsection{Integrating the Data}

A clear advantage of complex, longitudinal mixed methods design is the ability to iteratively draw on different strands and phases of the research to refine the specific methods and questions used, and identify and address new avenues of interest. Table 3 shows the methodological design of the project. The use of mixed methods enabled us to examine the intricacies of family lives while simultaneously observing statistical patterns. Thus we were able to identify both practices idiosyncratic to individual families, and more generalisable trends representing practices common in multiple families; and we were able to hypothesise about the underlying reasons for and meanings behind statistical findings based on in-depth knowledge generated in discussions and observations of family practices.

Table 2 Sample characteristics for the survey strand

\begin{tabular}{|c|c|c|c|}
\hline Characteristic & & $\%$ Wave 1 (unweighted) & $\%$ Wave 2 (unweighted) \\
\hline \multirow[t]{8}{*}{ Child age } & 10 & 14.5 & 11.5 \\
\hline & 11 & 14.5 & 13.5 \\
\hline & 12 & 14.2 & 13.9 \\
\hline & 13 & 14.8 & 13.3 \\
\hline & 14 & 15.0 & 12.9 \\
\hline & 15 & 14.7 & 15.5 \\
\hline & 16 & 12.6 & 10.9 \\
\hline & 17 & - & 8.8 \\
\hline \multirow[t]{3}{*}{ Child gender } & Male & 48.4 & 50.4 \\
\hline & Female & 51.5 & 49.6 \\
\hline & Other & 0.1 & 0.1 \\
\hline \multirow[t]{4}{*}{ Parent gender } & Male & 28.3 & 28.0 \\
\hline & Female & 71.5 & 71.9 \\
\hline & Other & 0.1 & 0.1 \\
\hline & Missing & 0.1 & 0.0 \\
\hline \multirow[t]{2}{*}{ Parent ethnicity } & White British & 86.0 & 90.4 \\
\hline & BAME & 14.0 & 9.6 \\
\hline \multirow[t]{6}{*}{ Socio-economic grade } & A & 6.1 & 7.3 \\
\hline & $\mathrm{B}$ & 21.1 & 20.1 \\
\hline & $\mathrm{C} 1$ & 26.9 & 26.8 \\
\hline & $\mathrm{C} 2$ & 20.1 & 19.3 \\
\hline & $\mathrm{D}$ & 13.9 & 15.3 \\
\hline & $\mathrm{E}$ & 11.9 & 11.2 \\
\hline
\end{tabular}


Table 3 The research process

\begin{tabular}{|c|c|c|c|c|c|c|c|c|c|}
\hline & \multicolumn{8}{|c|}{ Qualitative textual and visual evidence } & \multirow{7}{*}{$\begin{array}{c}\text { Final } \\
\text { analysis } \\
\text { to } \\
\text { combine } \\
\text { data from } \\
\text { all phases }\end{array}$} \\
\hline Quarter & Q1 & Q2 & Q3 & $\mathrm{Q} 4$ & Q5 & Q6 & Q7 & $\mathrm{Q} 8$ & \\
\hline Phase & \multicolumn{4}{|c|}{ In-depth study with families } & & & \multicolumn{2}{|c|}{ Interviews } & \\
\hline Influence & & & & & 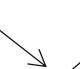 & & & & \\
\hline Phase & & & $\begin{array}{c}\text { Survey } \\
1\end{array}$ & & $\begin{array}{c}\text { Survey } \\
2\end{array}$ & & $\begin{array}{c}\text { Survey } \\
3\end{array}$ & & \\
\hline Quarter & Q1 & Q2 & Q3 & $\mathrm{Q} 4$ & Q5 & Q6 & Q7 & Q8 & \\
\hline & & & Qua & ative & erical e & & & & \\
\hline
\end{tabular}

Adapted from Castro et al. (2010); Q - year quarter

\subsection{Ethical Considerations}

Ethical approval for the research was obtained from the University of Leeds. ${ }^{3}$ Informed consent was obtained from participants (parents, children and other family members) in both strands of the study; assent was monitored throughout the qualitative study with particular attention to younger children's verbal and non-verbal cues around their willingness to continue participation. All participants were informed of their right to withdraw from the study at any point, and to refuse participation in any activities or to answer any questions that they did not want to. Pseudonyms and composite case studies are used throughout to avoid the possibility that individual participants or families might be identifiable.

\section{Findings}

Based on analysis of both strands of the project, a four-dimensional model is proposed covering different aspects of children's experience of and participation in intra-family sharing. This model emerged from analysis of the qualitative data, and was tested by a combination of checking the qualitative data for counter-examples, and seeking validation based on statistical analysis of related variables in the quantitative data. The four dimensions can be understood as falling into two categories, relating to whether they represent children's roles and experiences within the family (family specific dimensions), or whether children's experiences in the dimensions relate to the wider societal context and children's roles and experiences within and also beyond their family (contextual dimensions). This distinction is drawn because it helps to highlight the complexity of 'family' (and even more so of 'household') resource allocation; in reality what happens within the household or family influences and is influenced by a wide range of external factors which shape 'private' as well as 'public' behaviours and practices. Thus the first two dimensions - stakeholders (including those beyond the immediate family) and participation (including participation in family and in wider societal processes) can be understood as contextual; they relate to the broader cultural influences, social networks and norms within which families are operating. The second two - processes (the patterns of interaction within families) and outcomes (how different family members access and influence the use of resources) - are family-specific in that the relate to what happens within the family setting, but are strongly influenced by, and have to be understood as occurring within, the

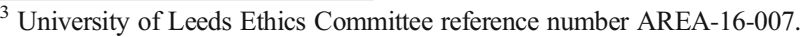


contextual dimensions. These four dimensions are now discussed in turn. Each section begins with some example cases illustrating key features of the dimension of the model. These arise from the research findings but are based on composite cases and a combination of qualitative and quantitative analysis.

\subsection{Stakeholders}

In a group interview, Fiona's family discussed exchanging gifts with extended family. They noted that some family members continued sending gifts to nieces and nephews until they were 21, while others stopped once they reached 18. Mark, Fiona's father, remarked that he was glad their children were the youngest in the extended family as this had enabled them to take their cues from other people and avoid family arguments.

Sarah, Rose's mother, had recently separated from Rose's father. In an individual interview she talked about her financial arrangements since the separation. Although her ex-partner was sending maintenance money, she was very aware that he expected that all of this money would be spent directly on the children, and was suspicious of her using it on other expenses. As a result, she was anxious about how she should use the money. She talked about struggling with the mortgage and bills as she did not believe he would view spending on these as spending 'on the children'.

During a family interview Celia, Arlette's mother, mentioned that she had 'nothing' before she formed a relationship and moved in with her partner. Arlette and Steve (her younger brother) quickly interrupted to say she - and they - still had nothing; although they could use his resources, this did not translate for them into a sense that they 'owned' them in a meaningful way

This dimension of the model is concerned with the range of people who are important contributors to, and consumers of, family resources. Findings in this dimension reflect the wider research base (e.g. The Children's Society 2017) in challenging the assumptions that parental income represents the sole input into children's material living standards, and that people living within the household are the only consumers of the resources acquired through this input. All families participating in the study identified a wide range of stakeholders - both within and outside their household(s) and family(ies) - who played important material and symbolic roles in the sharing of family resources. The three examples above highlight some of the multiple meanings and impacts which extended family can have upon 'family' resources and decisions. In the first example above, the exchange of gifts between family members was subject to unspoken rules and expectations, and had the potential to be a source of conflict. The experiences illustrated in the second example above highlight a theme which recurred throughout our qualitative research: contributions to the household's resources from non-resident family often come with weighty expectations. A more benign example of this came from another family, who noted that a gift (of money) from grandparents had come with the exhortation that it should be spent on luxuries rather than necessities; in both cases, however, the clear implication is that the utility of the gift cannot be assumed to be similar to a monetary gain of equal value that could be spent at the family's discretion. The situation illustrated in the third example above highlights the complexity of resource ownership within a household, and the importance of permanence as well as presence. While the mother interpreted her and her children's cohabitation with her (relatively) new partner as secure, and perceived her material situation to be improved, both children expressed reservations about this, indicating that they 
believed their access to 'his' resources was contingent on the continuing relationship and therefore did not amount to a real improvement in their own - or their mother's - material well-being.

In the first wave of the survey, the issue of contributors to children's material well-being was addressed through a question about who child participants would go to if they needed money or material resources. While the majority of children $(90.8 \%)$ reported that they would go to their parents, this was rarely children's only source of support. Nearly a quarter $(24.4 \%)$ reported that they would go to non-resident grandparents if they needed resources; nonresident parents $(7.8 \%)$, siblings within the household (6.3\%) aunts and uncles (5.4\%), step parents $(3.7 \%)$, and siblings outside the household (2.2\%) were also sources of material support to some children. Conversely, questions about regular financial gifts to non-resident family and friends were asked to investigate non-household consumers of family resources. $10.8 \%$ of parents reported giving regular gifts to non-resident family members totalling an average of $£ 1040$ per year. Thus stakeholders are important contributors to family resources but they are also important consumers of family resources, and cannot be assumed to be net benefactors.

In combination, these findings highlight the importance of distinguishing between family and household; between contributions to family resources which can be spent at the family's discretion and those which cannot; and between 'family', 'household', and 'individual' resources. Furthermore, stakeholders consume as well as contributing, and their contributions often come with strong expectations about the use of contributed resources. A further point, illustrated in the third example above, is that different members of the same family and/or household may have different perspectives on the same situation. This has implications for whose reports are used in studying children's and families' access to resources. What is clear is that a wide range of stakeholders contribute to children's overall material well-being.

\subsection{Participation}

In a family interview, Jerry and Jeff enthusiastically explained their family's approach to saving for their holiday, with each family member putting as much money as they could spare into a jar which would contribute to their spending money while they were away. This included the children contributing some of their pocket money or money they had received as gifts

Rose, who was living with her mother after her parents' recent separation, was aware that her mother's income was substantially reduced and that this resulted in a lot of stress for her mother. In an individual interview, she disclosed that she had stopped asking for a magazine she had previously liked to buy, to avoid putting additional strain onto the family budget

Celia and Mike discussed their frustration that they did not perceive Celia's children to help out with household jobs. In a couple interview, they gave details of a chart they had devised in an effort to get Arlette and Steve to help out more. Arlette, their daughter, was meant to cook dinner for the family once a week, while her brother was responsible for taking the dustbins out.

As noted above, previous research has established that parents engage in a wide range of activities designed to promote their children's material well-being. In particular, parents living in constrained circumstances go without necessities themselves to provide for their children. 
Less attention has so far been paid to the diverse roles that children can play in actively promoting their own and their family's material well-being, or attempting to mitigate the impact of material disadvantage. Three examples of children's activities in relation to family resources are provided above. These examples - children as contributing to family resources, economising to save family money, and contributing through unpaid labour - represent some of the important themes which emerged.

In line with previous literature, the qualitative strand of the research challenges the assumption that children are passive recipients of family resources. Rather, in all of the families involved in the study, children were active contributors. Their contributions ranged from donating pocket money and gifts of money to communal family expenses (as in the first example above), to getting a job in order to earn money to cover either their own or their family's expenses. This latter option was a source of frustration for some of the younger participants, as they were below the age at which they could legally get a paid job. However, even in these cases children detailed creative strategies they used to acquire resources - for example one girl described participating in multiple research projects for which she often received money or vouchers, and doing odd jobs for her aunt in return for cash. In wave 1 of the survey, children were asked to identify any activities they had undertaken to contribute to their family's resources. $8.1 \%$ reported giving their own money to other people in their family (or to a communal family pot); $10.7 \%$ reported getting a job to earn money for themselves, and $1.8 \%$ reported getting a job to give money to their family; $6.9 \%$ had asked people who they did not live with for money; and $1.7 \%$ and $1.5 \%$ respectively had stolen to meet their own, or their family's, needs.

The second example, of Rose going without her magazine, highlights children's roles in economising. This was investigated in the second wave of the project survey, in which children were asked to identify how often they had engaged in any of six economising behaviours (identified through the qualitative fieldwork and background literature to be the most relevant), during the past six months, as a result of them and their family not having enough money. Findings are presented in Table 4. The frequency with which children reported ever having engaged in these behaviours ranged from $11.4 \%$ having stolen at all in the past six months, to $47.2 \%$ having pretended to friends that they did not want to do something which cost money. For some of these activities, children were actively engaged not only in economising, but in hiding their (perceived) lack of resources and their economising behaviours by pretending to friends or family that the lack of resources reflects preference rather than constraint. Findings

Table 4 Children's economising activities (missed out due to a lack of family money) - \% children

\begin{tabular}{lllllll}
\hline Economising activity & Never & Very rarely & Rarely & Occasionally & Often & Very often \\
\hline $\begin{array}{l}\text { Missed out on a school trip or an after-school } \\
\quad \text { class or activity }\end{array}$ & 69.0 & 11.6 & 7.9 & 9.5 & 0.8 & 1.1 \\
$\begin{array}{l}\text { Worn clothes or shoes that are old and worn } \\
\quad \text { out, or that don't fit any more }\end{array}$ & 60.4 & 17.2 & 8.0 & 11.2 & 2.6 & 0.5 \\
$\begin{array}{l}\text { Pretended to family that they don't need } \\
\quad \text { something }\end{array}$ & 54.7 & 14.6 & 10.3 & 16.2 & 3.0 & 1.0 \\
$\begin{array}{l}\text { Pretended to friends that they don't want to } \\
\quad \text { do something }\end{array}$ & 52.8 & 12.9 & 10.5 & 19.0 & 3.4 & 1.2 \\
$\begin{array}{l}\text { Stolen money or goods from someone or } \\
\text { from a shop }\end{array}$ & 88.6 & 3.8 & 3.1 & 3.7 & 0.6 & 0.2 \\
\begin{tabular}{l} 
Not eaten, or eaten less than they wanted to \\
\hline
\end{tabular} & 75.2 & 8.6 & 5.5 & 8.1 & 1.5 & 0.9
\end{tabular}




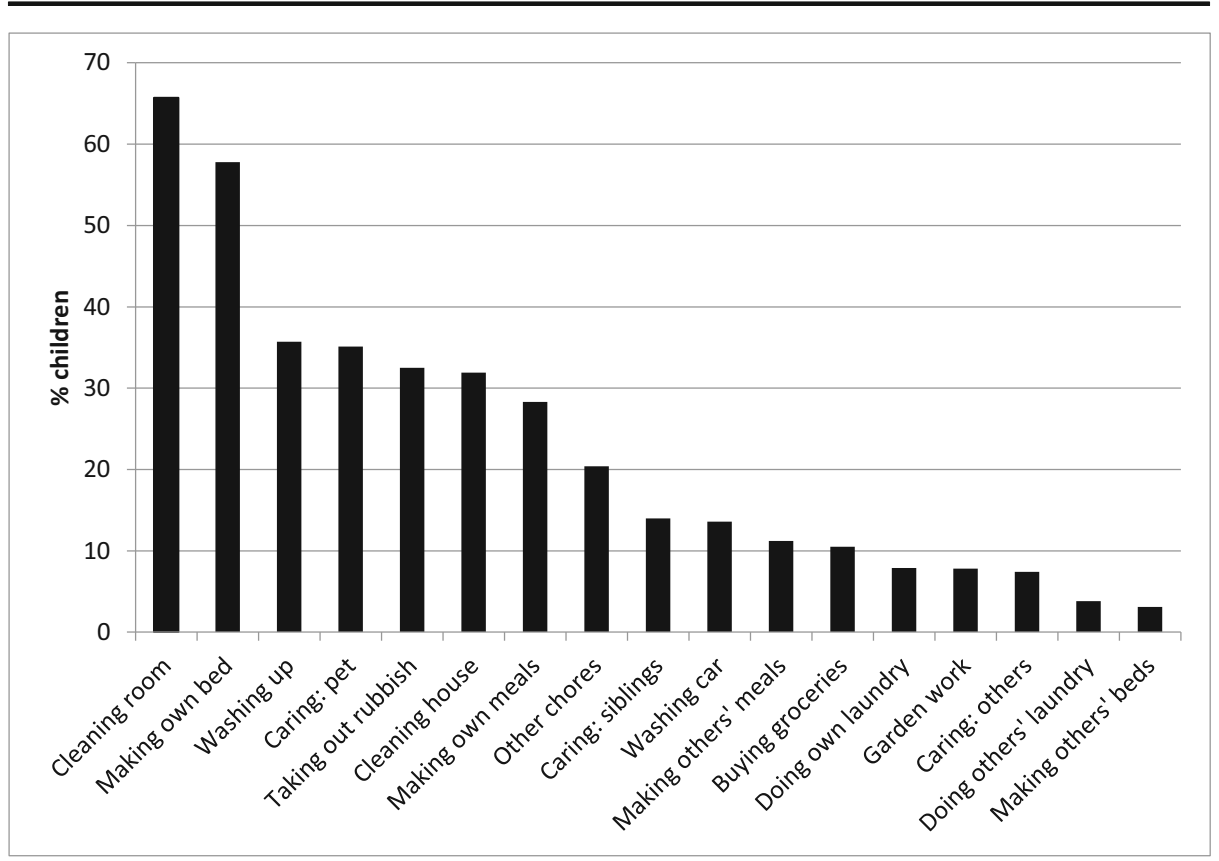

Fig. 1 Children's contributions to household work

suggest that not only are a substantial minority of children involved in economising, but that parents and other adults may not be aware of this.

The final example in this section shows children as active contributors to household maintenance. In the second wave of the survey strand, we investigated the unpaid household work undertaken by children. Participants were asked to identify which from a list of household tasks they did, and an approximate amount of time spent on household tasks on an average school day, weekend day during term time, and day during school holidays. Figure 1 shows the percentage of children reporting that they undertook the different types of household task. In terms of time spent on household work, the median amount of time children reported spending on these tasks was $30 \mathrm{~min}$ on week days and holidays, and $60 \mathrm{~min}$ on weekend days. ${ }^{4}$ These findings highlight the importance of considering children as active contributors to household maintenance, rather than passive drains on parental resources.

This section has highlighted the importance of understanding children as active participants in their own material well-being. Treating children as passive adjuncts to parents and as a simple drain on household resources will miss vitally important information about family material well-being; how this links to children's well-being (for example, via children participating in economising behaviours which may be hidden from their parents); and how children from a relatively young age are actively contributing to family and household maintenance.

\footnotetext{
${ }^{4}$ It is worth noting that strong gender differences were found in the nature and extent of children's contributions, which will be explored in more detail in future publications.
} 


\subsection{Processes}

In a family interview, Vercos' parents, Ana and James, were describing their decision to move Vercos from a state school to a private school. Ana began to discuss the changes they had made to their financial arrangements to pay the school fees, when James interrupted to say that he did not want this topic to be discussed

In an individual interview, Rose's mother Sarah described how she was moving to a new house as a result of a decline in family income following her separation from Rose's father. She described having to downsize from a four- to a three-bedroom house, meaning that George and Daniel, Rose's younger brothers, would have to share a bedroom. Sarah discussed this with them, but due to the restrictions on her income was not able to consider their preference for separate rooms in her final decision

In a family interview, Jeff and Jerry, and their parents Florence and Bob, described how they had decided on their holiday destination. As a result of a large monetary gift from Florence's mother, they were able to have a more expensive holiday than usual. Florence and Bob planned the holiday to America as a surprise for Jeff and Jerry. They chose this destination because they had heard Jeff and Jerry talking about wanting to go to America

Fiona's brother Charlie, who was five years older than her, got his first mobile phone when he was 15. In an interview with Fiona and her mother Stephanie, they described the decision to get Fiona a mobile phone at 13. Initially her parents had believed she should wait until she was the same age as Charlie had been, but Fiona persuaded her parents that lots more young people owned phones at 13 now than had five years ago, meaning that she would be excluded from her peer group if she had to wait until she was 15

Processes of family sharing relate to the ways that families, or different individuals or subgroups within families, go about making decisions which relate to how to use and distribute family resources. The four examples above highlight four broad types of process which were identified in the qualitative strand and validated in the survey strand of the research. While these approaches are by necessity generalisations, and it is unlikely that any family draws exclusively on one approach, qualitative and quantitative data indicate that many families may have a preferred or habitual approach to the process of making decisions about money and resources. The four approaches identified were:

- Authoritarian: processes taking an authoritarian style are characterised by children having low awareness of their family's financial situation and decisions about resources, and low levels of influence over such decisions. Parent(s) make the decision based on their own conception of what should happen, and the influence of other family member(s) in terms of their preferences or interests is minimal and/or unclear. This is illustrated in the first example above.

- Informational: this style is characterised by high levels of awareness, but low levels of influence. Parent(s) enacting an informational style may inform their children of the circumstances surrounding a decision about family resources, and of the decision which is reached; but children's views and preferences are not a key influence in the decision that is made. The second example above was categorised as informational, with this style 
being adopted because constraints on family resources precluded a consideration of children's opinions and preferences.

- Preferences-based: characterised by low levels of awareness but high levels of influence, the preferences-based style involves parental decisions which may not be discussed or explained to children, but which are strongly informed by children's views and preferences. Parent(s) glean these from observations and conversations with children which are not (overtly) related to the decision in question, and incorporate a consideration of these preferences into their decision making process without communicating with the child(ren) about the process. The third example above was classed as interests-based.

- Participatory: this style involves high awareness and high influence on the part of children. Participatory processes involve overt discussions among the relevant stakeholders about the decision, and an active role for children in shaping the decision itself. While this does not mean children's views and preferences are prioritised over those of adults, participatory processes do not treat such views and preferences as subordinate to those of adult(s); children's perspectives are treated with respect. The final example above illustrates this approach.

It should be noted that families in the qualitative study did not in general consciously adopt one of these strategies, and indeed their reports and discussions about family sharing processes were often contrasting over time and at odds with observational evidence. For example, in one family, Ana (the mother) stated in an individual interview that she and her husband openly discussed and equally shared resources, but in another interview said that she was not able to discuss their overall family income because James was reluctant to talk to anyone, including her, about family money. It is also important to note that children's awareness and influence must be understood in relation to the quality of their experience. Indeed, children reporting quantitatively high levels of awareness and influence may not be satisfied with this situation for example, in the case of young carers who may be forced into a situation of bearing a level of responsibility that is not aligned with their capacity or preferences. A high level of awareness and influence in this model, then, is characterised by being respectful of children's active roles in understanding and participating in their material well-being, but which is also aligned with the child's preferences and capacity.

Different process styles were confirmed in the survey data through cluster analysis, using two questions relating to children's perceptions of whether everyone in their family had a fair say in decisions about the use of family resources, and whether they had a good understanding of their family's material situation. Overall, $34.5 \%$ of children reported a broadly authoritarian style, while $20.7 \%$ reported an informational style, $12.1 \%$ reported a preferences-based style, and $32.7 \%$ reported a participatory style. Children were asked to report on whether they were involved in a wide range of different types of family decisions about resource use - ranging from whether the child was involved in selecting their own clothing and shoes, to whether they were involved in major financial decisions such as taking out a mortgage. The proportion of children reporting that they were involved in each decision according to sharing style are shown in Table 5. In each decision, the percentage of children reporting that they were involved was lowest for those identified as having an authoritarian approach, and highest among those identified as having a participatory approach.

The different styles of family sharing detailed above complement the previous section in highlighting that children are active participants in their family's material well-being, both in relation to involvement in decisions and developing impressions of how things are done within their own family. Two factors - children's level of understanding and the extent to which their 
Table 5 Children's involvement in family resource decisions by sharing process type

\begin{tabular}{llllll}
\hline Decision & Authoritarian & Informational & Preferences-based & Participatory & Overall \\
\hline Expensive family purchases & 5.4 & 5.6 & 19.1 & 25.1 & 13.5 \\
Everyday family shopping & 42.7 & 55.9 & 64.1 & 69.2 & 56.7 \\
Borrowing money (e.g. mortgage) & 1.0 & 2.2 & 4.6 & 5.0 & 3.0 \\
Use of space in the family home & 24.1 & 34.5 & 39.1 & 53.9 & 37.8 \\
Family holiday destinations & 43.9 & 43.2 & 65.7 & 68.9 & 54.6 \\
Large expenses for child & 40.7 & 46.9 & 58.7 & 66.1 & 52.5 \\
Child's clothes and shoes & 75.8 & 81.3 & 82.5 & 85.0 & 80.7 \\
Not involved in any decisions & 14.6 & 9.3 & 2.2 & 1.6 & 7.7 \\
\hline
\end{tabular}

opinions and preferences influence family decisions - stand out as important in differentiating between approaches to sharing family resources.

\subsection{Outcomes}

Stephanie and Mark, Fiona's parents, spoke a lot about different approaches within their extended family to giving gifts. They reported that Mark's sister gave her children presents of equal financial value, while they preferred to spend according to the gifts their children most wanted, rather than equal value. They suggested that Mark's sister preferred getting presents of equal value because she had perceived Mark as getting more than she did when they were children, which she had felt was unfair

Jerry had a disability which restricted his use of his right arm. In separate individual interviews, both Jerry and his mother Florence discussed different needs that he had, such as adaptations to their house, and how he would need an adapted car when he was old enough to drive. Both believed that because they had the financial resources to afford these adaptations, his life was not - and was not likely to be in the future - particularly seriously impacted by his disability

In an interview with Nick and his twin brother Paul, Nick described his reasons for giving up his paid job. He was unhappy about the pay he received for working in a fish and chip shop, because at 16 , despite doing identical work to his older colleagues, he was paid a much lower rate since the UK minimum wage varies according to age

There is a great deal of academic and popular debate about what constitutes fairness in the distribution of resources at global and national levels, and this issue was also evident within the families participating in the study. But while different perspectives on what constituted a fair distribution were evident, it was also notable that all families participating in the qualitative strand of the project placed a high level of importance on achieving fair outcomes. In the first example above, Stephanie and Mark's interactions highlight an attentiveness to fairness, and an awareness of - and interest in - different interpretations of this. Such themes were evident across the families who participated in our qualitative study. In one family the twins Nick and Paul spoke about receiving monetary rewards for recent exam results. Although they had received different amounts of money, they believed this outcome to be fair because they had achieved different grades, which they felt reflected the effort they had put in. The third example above highlights the importance which children place on fairness not only within their families, but also within wider society. As noted above, some young people expressed frustration that they 
were not legally able to engage in paid employment. But even for those young people who could work, there was a strong awareness that their pay was rarely commensurate with that of older colleagues doing the same work, and this was a frequent source of anger. The second example above represents the complex interacting factors which contribute to (not) achieving equity in opportunities and resources. Jerry's disability was not perceived by him or his mother to pose a significant threat to his access to social justice - but they were aware that this was a result of their ability to pay for modifications to their environment which enabled equal access for Jerry, and such modifications may not be as accessible to children in poorer families.

Using the survey data it was possible to examine how different types of sharing process interacted with perceptions of fairness in how families shared resources. In addition to the two questions noted above which were used to allocate children to different process styles, children were asked how far they agreed that everyone in their family received a fair share of the family's resources. Figure 2 shows the distribution of responses within each process style. While few children overall reported that they disagreed or disagreed strongly with this statement, the vast majority of those who did disagree were identified as having an authoritarian or informational style. Similarly, the minority of children who reported strong agreement, and those who reported agreement, were much more likely to be identified as having a preferences-based or participatory style. This suggests that a higher level of awareness of and involvement in decisions about family resources, in line with children's preferences and capacities, may result in a greater sense of perceived fairness in how these resources are allocated and used.

\section{Discussion}

The purpose of this article has been to propose a child-centric model of intra-family sharing based on children's own perspectives and reports. The four dimensions of the model stakeholders, participation, processes, and outcomes - provide a lens through which a more

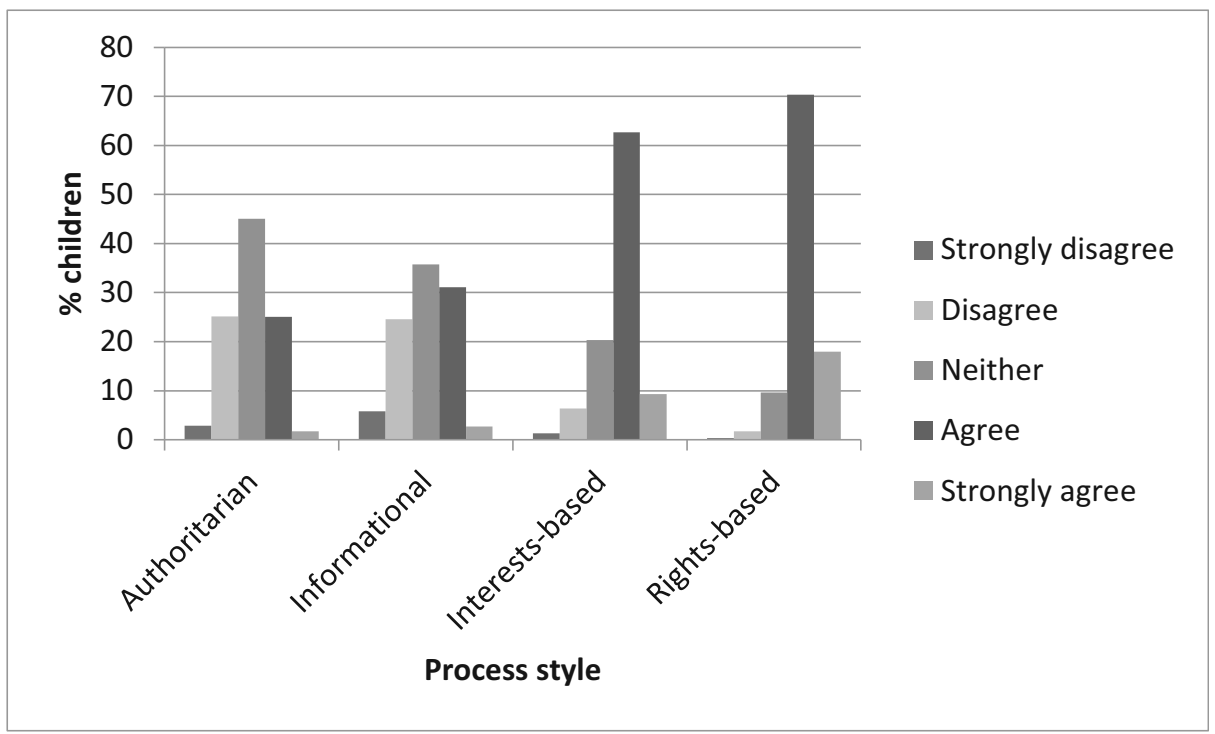

Fig. 2 Perceptions of the fairness of family resource distribution by process styles 
holistic impression of intra-household sharing within families with children can be obtained. Children's active roles in forming and maintaining family relationships, contributing to their own and their family's material well-being, contributing to decisions about resources, and interpreting their material situation are evident in each dimension of the model. While children have traditionally been treated as passive adjuncts to parents in studies of material well-being, this is rarely an accurate portrayal and decreases in accuracy as children and families develop and change over time. Hence the model has an important temporal dimension; all aspects of the model are subject to change over time, partly in relation to children's developing capacities, but probably also in relation to changes in family formation, extended family composition, relationships outside the family, and a wide range of other factors. In this section, the implications of the model proposed here are examined, followed by a discussion of the limitations of this research.

\subsection{Implications}

The research presented here has implications for academics, but also beyond academia for policy makers and practitioners working to promote children's material well-being and, more broadly, children's rights.

In the background section, the limitations of reliance on household income and parental reports are discussed. The findings confirm these limitations, providing strong support to the growing consensus that poverty is multidimensional in nature, and multidimensional measures are required to capture the range of ways that it is manifest in and impacts upon people's lives (e.g. see OPHI 2015). A focus on resources - such as household income - is vital to understanding children's material well-being (Cooper and Stewart 2013), but only provides part of the picture. In addition, the networks within and outside households, of family and other people, can represent important contributors to and consumers of resources. Such networks impact a family's, and a child's, capacity to translate 'family' material resources into personal resources and outcomes. It should be stressed here that the contributions of family external to the household is frequently sporadic and conditional in nature, and is balanced with the consumption of 'household' resources by extended family. Support from extended family is by no means a route by which parent and children's material well-being can be guaranteed. Children take part in, and reflect on their participation in, the processes involved in acquiring and sharing family resources, and in many instances this participation is partly or entirely invisible to other people in the child's household. Previous research establishes that parents forego their own needs to provide for their children (Main and Bradshaw 2018; Middleton et al. 1997; Ridge 2002). This research complements this finding and adds mixed-methods evidence to previous qualitative studies (e.g. Ridge 2002; Middleton et al. 1997) which have established that many children also forego their needs, often without the knowledge of their parents, in response to family financial hardship. The nature and effects of such economising, whether secretive or otherwise, bear further examination - and the Fair Shares and Families project dataset will enable such investigation. Children's agency is an important consideration in understanding child material well-being, as are the ways in which this agency is exercised and constrained in the context not only of their status as children, but also other, interacting identities such as poverty status and gender (which as noted above will be examined in more depth in future analyses). The effects of the ways in which individual children contribute to and consume family resources demand further study, and such study has the potential to identify and make recommendations towards the amelioration of social injustices. 
Academic research can highlight and enumerate some types of social injustice mentioned above, but policy action is needed to effect social change and mitigate the effects of experiences of injustice. One important method for achieving this is via the tax and benefit system. Currently in the UK this system draws heavily on household income and parental labour market activity to determine eligibility. As Davies (2015) recommends, current provision could be usefully supplemented by a consideration of the complex roles of extended family (such as grandparents) in supporting the material well-being of families with children, and in consuming the resources classified as belonging to the 'household'. The provision of financial support by non-household family and friends may have the unintended and undesirable consequence of pushing non-household contributors into poverty. Similarly, the obligations of families to contribute resources to members outside of the household may render families who apparently have sufficient resources impoverished. A reliance on contributions from family and stakeholders outside of the household has been demonstrated here to be problematic due to the sporadic and conditional nature of such contributions, and the requirement for reciprocity. A potential solution could be the provision of increased financial support, whether to enable families to provide for themselves without reliance on extended family, or to extended family members in return for their contributions of money and labour. Conversely, parents and children without access to the support of extended family and social networks (whether this is because no such networks exist, or their networks have limited capacity to supplement their resources) may suffer disproportionately as a result of low incomes. Additional support such as increased incomes and subsidised high-quality child care could provide valuable additions to the resources available to families in this situation. Certainly, a careful consideration of the implications of changing family structures and practices is indicated, in relation not only to how entitlements are calculated but also which resources are considered to be 'individual' property and which can reasonably be ascribed to the 'family' or 'household'.

This research has highlighted the varied, active roles children play in negotiating their material well-being. Children's rights under the United Nations Convention on the Rights of the Child (UNCRC) include the right to participation (e.g. Article 12), which is often overlooked in concepts, definitions and measures of child poverty (e.g. Main 2018a). Participation rights, though, cannot be fully understood in isolation from provision and protection rights; UNICEF (1989) stresses that all UNCRC rights are inseparable. The relationship between children's participation in family resource sharing decisions and child poverty is an important topic for further examination, and children's active participation in mitigating the effects of poverty, while an example of agency, demonstrates that participation in a context of deprivation may be damaging to children's family relationships and well-being. Children's participation must be in a context of families having adequate resources to provide for children's needs, and to protect children from harm. As a result, and in line with the previous paragraph, redistribution to increase the incomes available to families with fewer resources would be an important step in beginning to address societal injustices. Only in this context can families adopt approaches to resource sharing which promote within-family equity.

\subsection{Limitations}

This paper has drawn on mixed methods, comprising an in-depth qualitative study with eight families, and a representative survey of 1000 children in England. While efforts have been made to support the proposed model drawing on both qualitative and quantitative data, the quantitative analysis presented here have been descriptive in nature. This is because the 
purpose of this paper is to provide an overview of the model drawing on both quantitative and qualitative analysis. More advanced quantitative analyses exploring the different aspects of the model, and interactions between different parts of the model, are indicated. Such analyses are forthcoming, but are beyond the scope of this paper. Similarly, much more detailed analyses of the qualitative data will be presented in future papers; for example, the potential similarities between some of the approaches to family sharing and Baumrind's (1989) work on parenting styles would prove an interesting topic for future investigation. Finally, the aim of the childcentric model has been to reflect the experiences of a broad cross-section of children in England, drawing on both in-depth qualitative data and large-scale survey data. Generalisation beyond the English context is not possible, and the applicability of the model to sub-groups of children likely to have very different experiences of intra-family resource sharing (for example young carers) is unclear. Further research exploring the value of the model in other contexts and to specific sub-groups of children would be a valuable development of this work.

Acknowledgements Thanks to Sorcha Mahony and Susana Cortes-Morales for contributions to the analysis and fieldwork informing this article. All mistakes remain my own

Open Access This article is distributed under the terms of the Creative Commons Attribution 4.0 International License (http:/creativecommons.org/licenses/by/4.0/), which permits unrestricted use, distribution, and reproduction in any medium, provided you give appropriate credit to the original author(s) and the source, provide a link to the Creative Commons license, and indicate if changes were made.

\section{References}

Baumrind, D. (1989) Rearing competent children. In Damon, W. (Ed) The Jossey-bass social and behavioural science series: Child development today and tomorrow (pp349-378). San Francisco: Jossey Bass.

Bennett, F. (2013). Researching within-household distribution: Overview, developments, debates, and methodological challenges. Journal of Marriage and Family, 75(3), 582-597.

Bradshaw, J. (2016). The well-being of children in the UK. Bristol: Policy Press.

Burchardt, T., \& Karagiannaki, E. (2018). 'Within-household allocation of resources: Implications for deprivation and poverty across Europe'. Keynote presentation delivered at the Foundation for International Studies on Social Security $25^{\text {th }}$ Anniversary Conference in Sigtuna (pp. $4^{\text {th }-6}$ th June 2018). Sweden.

Castro, F. G., Kellison, J. G., Boyd, S. J. and Kopak, A. (2010 'A methodology for conducting integrative mixed methods research'. In Journal of Mixed Methods Research vol.4 no.4 pp342-360.

Chzhen, Y., de Neubourg, C., Plavgo, I., \& de Milliano, M. (2014) Understanding child deprivation in the European Union: The multiple overlapping deprivation analysis (EU-MODA) approach. UNICEF Office of Research Working Paper no.WP-2014-18. Florence: UNICEF.

Cooper, K., \& Stewart, K. (2013). Does Money Affect Children's Outcomes? A systematic review. In Report for the Joseph Rowntree Foundation. York: JRF.

Davies, H. (2015). Shared parenting or shared care? Learning from children's experiences of a post-divorce shared care arrangement. In Children and Society, 29(1), 1-14.

Dermott, E., \& Main, G. (2018). Poverty and social exclusion in the UK-Volume 1: The nature and extent of the problem. Bristol: Policy Press.

Griggs, J., \& Walker, R. (2008). The costs of child poverty for individuals and society: A literature review. York: Joseph Rowntree Foundation.

Huebner, E. S. (1991) 'Initial development of the student's life satisfaction scale'. In School Psychology International vol.12 no.3 pp231-240.

Main, G. (2013) A child-derived material deprivation index. Unpublished $\mathrm{PhD}$ thesis submitted to the University of York September 2013.

Main, G. (2018a). Money matters: A nuanced approach to understanding the relationship between household income and child subjective well-being. In Child Indicators Research available online from June 2018. https://doi.org/10.1007/s12187-018-9574-z. 
Main, G. (2018b). Fair shares and families study. In Poverty: The policy journal of the Child Poverty Action Group vol.160.

Main, G. and Bradshaw, J. (2016) 'Child poverty in the UK: Measures, prevalence and intra-household sharing'. In Critical Social Policy vol.36 no.1 pp38-61.

Main, G., \& Bradshaw, J. (2018). Improving lives? Child poverty and social exclusion. In Dermott, E. and Main, G. (2018) Poverty and Social Exclusion in the UK - Volume 1: The nature and extent of the problem. Bristol: Policy Press.

Middleton, S., Ashworth, K., \& Braithwaite, I. (1997). Small Fortunes: Spending on children, childhood poverty and parental sacrifice. York: Joseph Rowntree Foundation.

Olah, L. S., Hobson, B., \& Carlson, L. (2017). Synthesis of main findings in the families and societies project. FamiliesAndSocieties Working Paper Series no.77. Available online from http://www.familiesandsocieties. eu/wp-content/uploads/2017/06/WP77OlahHobsonCarlson2017.pdf.

OPHI. (2015). Measuring multidimensional poverty: Insights from around the world. Oxford: OPHI.

Ridge, T. (2002). Childhood poverty and social exclusion. Bristol: Policy Press.

The Children's Society. (2017). Understanding childhoods: Growing up in hard times. London: The Children's Society.

UNICEF. (1989). The united nations convention on the rights of the child. London: UNICEF UK.

Publisher's Note Springer Nature remains neutral with regard to jurisdictional claims in published maps and institutional affiliations. 